\title{
Clinical and scientific letters
}

Please submit letters for the editor's consideration within three weeks of receipt of Clinical Medicine. Letters should ideally be limited to 350 words, and sent by email to: clinicalmedicine@rcplondon.ac.uk

\section{Case series of short synacthen tests supports using} 9 am cortisol level to exclude adrenal insufficiency

Short synacthen tests (SSTs) are frequently performed to diagnose or exclude adrenal insufficiency, yet they are inconvenient and expensive. In the NHS, each dose of synacthen costs $£ 45.71$, following a recent 15 -fold price increase. ${ }^{1}$ It is widely held that a high normal 9 am serum cortisol level is necessary to be able to exclude adrenal insufficiency without a SST. We reviewed all 12 published studies that correlate $9 \mathrm{am}$ cortisol levels with the SST. These studies require a cortisol concentration of at least $243-500 \mathrm{nmol} / \mathrm{L}$ to guarantee a normal SST, even though the lower limit of normal for 9 am cortisol is significantly lower. These conservative cutoffs were chosen to guarantee $100 \%$ sensitivity, and a normal SST was typically defined as a 30 -minute stimulated cortisol concentration above $550 \mathrm{nmol} / \mathrm{L}$. However, a 2013 study assessing five different modern cortisol assays in healthy volunteers found much lower 2.5th percentile normal limits for 30-minute SST response, ranging from $418 \mathrm{nmol} / \mathrm{L}$ to $469 \mathrm{nmol} / \mathrm{L}$ (male participants), with the exception of the Roche Modular assay, which read much higher. ${ }^{2}$

We reviewed all 182 SSTs performed during one year in our trust on medical inpatients and endocrinology outpatients. Only 79 SSTs followed a prior 9 am cortisol measurement. Of 166 patients with either a 9 am cortisol or a SST basal cortisol above the assay $9 \mathrm{am}$ lower limit of normal of $119 \mathrm{nmol} / \mathrm{L}$ (Siemens Centaur assay), 157 (94.6\%) had a 30-minute cortisol above $500 \mathrm{nmol} / \mathrm{L}$ and were judged as normal by the treating clinician. Of the nine patients with a 30-minute cortisol under $500 \mathrm{nmol} / \mathrm{L}$, only two commenced hydrocortisone anew after the SST. (In both of these patients, the stimulated 30-minute cortisol could be considered borderline low, at above 413 $\mathrm{nmol} / \mathrm{L}$. However, in both cases the 30 -minute incremental rise in stimulated cortisol was above $225 \mathrm{nmol} / \mathrm{L}$, which might imply that treatment was not necessarily required.) Two patients already receiving hydrocortisone continued to take it after the SST, and the other five patients continued without corticosteroid replacement. In summary, the SST did not change management in $98.8 \%$ of patients who had either a 9 am or a basal cortisol within the normal range. In interpreting our case series, we believe that consideration of how a borderline SST affected decision making in the clinical context is more relevant than applying a numerical cutoff for the SST that may not reflect the full range of normal variation.

When interpreting a 9 am cortisol level, one should remember to consider the true clinical pre-test probability of adrenal insufficiency. ${ }^{3}$ Since the 9 am cortisol and SST 30-minute cortisol levels have wide normal distributions, exact lower limits are difficult to absolutely specify. However, clinicians should be reassured that in most contexts, a 9 am cortisol above the assay lower limit of normal should be an adequate descriptor of normality, with the notable exceptions of critically unwell patients and women taking hormonal contraception, which increases cortisol-binding globulin ${ }^{2}$.

Given the universal pressures on clinical and financial resources, reduction in numbers of SSTs should be a safe and achievable goal. We recommend that individual hospitals adopt local policies to require a $9 \mathrm{am}$ serum cortisol measurement before considering a SST, and this should be an auditable quality measure. Additionally, we recommend adoption of a locally agreed assay-specific cutoff, above which a SST is not required, except in special circumstances, which should be discussed with the local endocrinology team.

BERNARD FREUDENTHAL Academic clinical fellow, Department of Endocrinology and Diabetes, Watford General Hospital, Watford, UK

DANIEL BEDER

Foundation year trainee, Department of Endocrinology and Diabetes, Watford General Hospital, Watford, UK

ARLA OGILVIE

Consultant endocrinologist, Department of Endocrinology and Diabetes, Watford General Hospital, Watford, UK

\section{References}

1 Joint Formulary Committee. British National Formulary (BNF) 70. London: Pharmaceutical Press, 2015.

2 El-Farhan N, Pickett A, Ducroq D et al. Method-specific serum cortisol responses to the adrenocorticotrophin test: comparison of gas chromatography-mass spectrometry and five automated immunoassays. Clin Endocrinol (Oxf) 2013;78:673-80.

3 Deeks JJ, Altman DG. Diagnostic tests 4: likelihood ratios. BMJ 2004;329:168-9. 